\title{
A Student-Designed Potentiometric Titration: Quantitative Determination of Iron(II) by Caro's Acid Titration
}

\author{
Joyce R. Powell, Sheryl A. Tucker, and William E. Acree, Jr.* \\ Department of Chemistry, University of North Texas, Denton, TX 76203-0068
}

\author{
Jennifer A. Sees and Lindsey H. Hall \\ Texas Instruments, P. O. Box 650311, Mail Station 301, Dallas, TX 75265
}

Oxidation-reduction titrations and potentiometric methods provide a convenient experimental means to quantitatively determine compositions of unknown mixtures containing oxidizable/reducible species. Over the past decade, numerous titration methods have appeared in this Journal (1-6) and in standard laboratory manuals (7-10) involving common titrants such as potassium dichromate, iodine, potassium permanganate, cerium(IV) sulfate, and sodium thiosulfate. As representative examples, Kaufman and DeVoe (3) devised a simplified redox method for total iron content by first reducing any iron(III) to iron(II) with metallic zinc, followed by potassium dichromate titration using sodium diphenylamine sulfonate as the indicator. Klett et al. (4) proposed a similar $\mathrm{Fe}$ (II)-Cr(VI) titration method, except that titanium(II) chloride was used to reduce all iron to the $2+$ oxidation state. Both methods generate waste solutions containing chromium, which should be disposed of by an environmentally safe method $(11,12)$. Chromium(III) is considered a "high hazard" ion, and may induce toxic effects. Similarly, chromium(VI) is very toxic and is also a suspected carcinogen $(11,12)$. Harris and Kratochvil (7) described the permanganimetric oxidation of iron and the iodometric determination of copper in brass. Pickering and Monts (6) described a rather novel laboratory experiment involving titration of the nonstoichiometric $\mathrm{WO}_{2.2-3.0}$ blue oxide, "mineral blue", with potassium permanganate. This latter method requires that the titration solution be heated, and chloride ions are known to interfere in potassium permanganate titrations.

\section{Overview of the Student Experiment}

The problem addressed in this student-designed laboratory experiment is to "determine the feasibility of using Caro's acid, $\mathrm{H}_{2} \mathrm{SO}_{5}$, as a titrant in the potentiometric determination of iron(II)." Specific items to be considered include (i) method of endpoint detection; (ii) shelf-life stability of titrant; (iii) accuracy, relative precision, and experimental uncertainty; and (iv) which common cations and/or anions (if any) interfere with the titration. Our experiment allows for student design, is inexpensive, poses no abnormal health risks, and does not require any unusual safety precautions beyond regular eye protection and the care students are expected to exercise in handling concentrated acid solutions and strong oxidizing agents. It allows students to work in teams to design a new analytical method to address the concerns associated with potentiometric titrations and endpoint determination. College professors teaching honors general chemistry, analytical chemistry, and/or instrumental analysis courses can employ the experiment with an

${ }^{*}$ Corresponding author. appropriate amount of instruction and direction by the laboratory supervisor. As educators, we realize the importance of teaching students not only how to use the apparatus and how to follow procedures, but also how to approach "real-world" problems utilizing the knowledge they have gained in the classroom. This lab serves that purpose because it uses ideas that are familiar even in general chemistry. It serves as a learning tool because it is designed to ensure success and build confidence in one's ability to design an approach to solve real-world problems. Moreover, the use of Caro's acid eliminates waste disposal concerns associated with potassium dichromate, and the long shelf-life of this reagent involves an interesting practical application of Le Chatelier's principle, which serves as an excellent teaching tool.

\section{Experimental Measurements}

We suggest that two lab periods be allotted for this experiment and that students work in pairs to facilitate discussion when problems arise. This enables experimental work to be divided into two parts. Preparation of Caro's acid solution, development of titration method and endpoint detection, standardization of Caro's acid, and quantitative determination of the iron(II) concentration of an unknown Mohr salt solution (if desired) are done the first day, leaving the studies of titrant stability and which common cations and/or anions (if any) interfere with the titration for the second laboratory period.

Students are instructed initially to pattern their experimental method after published procedures for standardization of potassium dichromate with Mohr salt, $\mathrm{Fe}\left(\mathrm{NH}_{4}\right)_{2}\left(\mathrm{SO}_{4}\right)_{2} \cdot 6 \mathrm{H}_{2} \mathrm{O}(3,4)$. Caro's acid titrant $(250 \mathrm{~mL}$, 1:10 PDSA $/ \mathrm{H}_{2} \mathrm{SO}_{4}$ mixture) is prepared by very slowly adding $25 \mathrm{~mL}$ of peroxydisulfuric acid (PDSA) to $225 \mathrm{~mL}$ of concentrated $\mathrm{H}_{2} \mathrm{SO}_{4}$, and the resulting solution is thoroughly mixed. Caro's acid is produced as a result of the hydrolysis of peroxydisulfuric acid with the water in concentrated sulfuric acid. The hydrolysis reaction produces one mole of Caro's acid and one mole of sulfuric acid per mole of peroxydisulfuric acid hydrolyzed (13). Exact quantities are not critical, as the titrant must be standardized against Mohr salt. CAUTION: As is the case with most strong oxidizing agents, contact with organic chemicals is to be avoided.

The standardization procedure involved dissolving a known weight of about $0.25 \mathrm{~g}$ of Mohr salt in $100 \mathrm{~mL}$ of distilled water, followed by addition of $10 \mathrm{~mL}$ of concentrated $\mathrm{H}_{2} \mathrm{SO}_{4}$ and $15 \mathrm{~mL}$ of concentrated $\mathrm{H}_{3} \mathrm{PO}_{4}$. Ten drops of a barium diphenylamine sulfonate indicator solution $(0.2 \%)$ was added. The resulting solution was slowly titrated and the potential recorded after each incremental addition of Caro's acid. The observed indica- 
tor color change was clear $\rightarrow$ violet. From the known weight of Mohr salt and volume of titrant used, the titer concentration (mg of Fe/mL of titrant) of Caro's acid was calculated. This value could then be used in the quantitative analysis of an unknown Mohr salt solution, which would be titrated in a similar manner. The cation/anion interference study differs only slightly from the standardization procedure, in that $0.25 \mathrm{~g}$ of the salt to be studied is added to the Mohr salt solution just before titration. The weight of the Mohr salt can be increased or decreased as necessary to give a suitable equivalence point volume of Caro's acid. CAUTION: burettes are to be filled below eye level.

\section{Discussion}

Student titration results typically show that the visual indicator change corresponds to within $0.2 \mathrm{~mL}$ of the potentiometrically determined endpoint. If the titration is monitored potentiometrically, one can compare this endpoint with that determined from the indicator color change. In addition, students can use the potentiometric data to construct first-derivative $(\Delta E / \Delta V$ vs. average volume of titrant), second-derivative $\left(\Delta^{2} E / \Delta V^{2}\right.$ vs. volume of titrant), and Gran ( $\Delta V / \Delta E$ vs. average volume of titrant) plots to help locate the endpoint (14-17).

The stability study is best left for the second laboratory period, as there will be insufficient time for noticeable degradation to occur during the first period. Our experience has been that standardizations performed after 7-10 days of storage differ only slightly from firstday determinations. After two weeks, however, degradation is visually noticeable, as the solution now contains numerous small bubbles $\left[\mathrm{H}_{2} \mathrm{SO}_{5} \rightleftarrows \mathrm{H}_{2} \mathrm{SO}_{4}+1 / 2 \mathrm{O}_{2}(\mathrm{~g})\right]$. Restandardization also shows that the titer value has decreased significantly. If significant decomposition is observed, students are asked to suggest ways to store Caro's acid so as to minimize this. The better students quickly see the solution of the problem as a practical application of Le Chatelier's principle. Decomposition is reduced by shifting the equilibrium to the left-hand side. This can be accomplished by transferring the unused titrant to a smaller sealed container so as to minimize the vapor space above the liquid solution. By minimizing vapor space, we have been able to store Caro's acid solutions for up to eight weeks with less than $5 \%$ decomposition. Titrant decomposition will not be a concern in the quantitative analysis portion of the laboratory experiment, since the unknown Mohr salt solution is titrated the same day as the original standardization. Similarly, the titer concentration determined from the second laboratory period will be used for all experimental work performed that day.

Over a two-semester period numerous inorganic salts have been added during the standardization procedure to screen for possible interferences. Salts studied thus far include the following (given within parentheses are the student-observed endpoint color changes associated with the diphenylamine sulfonate indicator):

$\mathrm{MnSO}_{4}$ (clear $\rightarrow$ dark violet), $\mathrm{Al}_{2} \mathrm{O}_{3}$ (cloudy white $\rightarrow$ light violet), $\mathrm{Cr}\left(\mathrm{NO}_{3}\right)_{3}$ (blue $\rightarrow$ dark violet), $\mathrm{Co}\left(\mathrm{NO}_{3}\right)_{2}$ (pink $\rightarrow$ violet), $\mathrm{NaNO}_{2}$ (clear $\rightarrow$ violet); $\mathrm{LiNO}_{3}$ (clear $\rightarrow$ violet), $\mathrm{SnCl}_{2}$ (white $\rightarrow$ violet $\rightarrow$ white),; $\mathrm{Zn}\left(\mathrm{NO}_{3}\right)_{2}$ (clear $\rightarrow$ violet), $\mathrm{MgCl}_{2}$ (clear $\rightarrow$ violet), $\mathrm{CaCl}_{2}$ (clear $\rightarrow$ violet), $\mathrm{CuSO}_{4}$ (blue $\rightarrow$ violet), $\mathrm{KNO}_{3}$ (light yellow $\rightarrow$ violet), $\mathrm{KBr}$ (cloudy white $\rightarrow$ light yellow), and $\mathrm{KCl}$ (clear $\rightarrow$ light yellow).

Students are at first quite surprised to see the various indicator changes, which can be rationalized to a large extent in terms of the added color imparted to the solution by the various transition metal ions. Of all of the cation/anion pairs studied, only tin(II) was found to interfere with the Caro's acid titration. Titration errors for the other cation-anion pairs were less than $1 \%$.

\section{Conclusion}

To our knowledge, our student-designed laboratory experiment is the first one to address the topic of screening for chemical interferences, which is an important "real-world" consideration in developing new analytical methods. Often, as educators, we are content to teach only fundamental principles and to instruct students how to use scientific instrumentation and follow established experimental procedures. Very seldom, at the undergraduate level, do we discuss the thought that goes into solving the more practical chemical problems that students encounter after graduation. Our titration method is designed in part to address such shortcomings. Students must design experimental methods and select measurements that answer the questions posed: namely, is Caro's acid a suitable titrant for the quantitative determination of iron(II), what is the storage stability of Caro's acid, and which common cation/anions (if any) interfere in the analysis. The basic approach presented here actively involves students in method development and can be incorporated into other laboratory experiments during the semester.

\section{Acknowledgments}

The authors thank Upward Bound Math and Science high school students Diana Voisinet and Andres Salazar for help with several of the preliminary cation/ anion interference titrations. The Upward Bound program is supported by a grant from the U.S. Department of Education.

\section{Literature Cited}

1. Ponraj, D. S.; Venkataraman, R; Raghavan, P. S. J. Chem. Educ. 1990, 67, 621.

2. Rice, G. W. J. Chem. Educ. 1990, 67, 430-431.

3. Kaufman, S.; DeVoe, H. J. Chem. Educ. 1988, 65, 183-184

4. Klett, L. D.; Black, A. H.; Parker, G.A. J. Chem. Educ. 1984, 61, 1020.

5. Selig, W. S. J. Chem. Educ. 1984, $61,80$.

6. Pickering, M.; Monts, D. L. J. Chem. Educ. 1982, 59, 693-694.

7. Harris, W. E.; Kratochvil, B. Chemical Separations and Measurements; Saunders College: Philadelphia, 1974; pp 75-91.

8. Sawyer, D. T.; Heineman, W. R.; Beebe, J. M. Chemistry Experiments for Instrumental Methods; John Wiley \& Sons: New York, 1984; pp 33-36.

9. Bott, S. G. This is Chemistry? 2nd ed.; Ginn: Needham Heights, MA, 1994; pp 181-186.

10. Beran, J.A.; Brady, J. E. General Chemistry: Principles \& Structure; John Wiley \& Sons: New York, 1990; pp 211-218.

11. Walton, W. A. J. Chem. Educ. 1987, 64, A69.

12. Prudent Practices for Disposal of Chemicals from Laboratories; National Academy of Sciences: Washington, DC, 1985.

13. Cotton, F. A.; Wilkerson, G. Advanced Inorganic Chemistry, 5th ed.; Wiley Interscience: New York, 1988; pp 524-525.

14. Gran, G. Anal. Chim. Acta 1988, 206, 111-123.

15. Boiani, J. A. J. Chem. Educ. 1986, 63, 724-727 and references listed therein.

16. Schwartz, L. M. J. Chem. Educ. 1987, 64, 947-950.

17. Peters, D. G.; Hayes, J. M.; Hieftje, G. M. Chemical Separations and Measurements; W. B. Saunders: Philadelphia, 1974; pp 378-380. 